\title{
Men's Knowledge of Anticipatory Guidance Topics: Results From a Nationally Representative Survey
}

\author{
Shawna J. Lee, PhD; Tova B. Walsh, PhD; Joyce Y. Lee, MSW; Richard Tolman, PhD; \\ Craig Garfield, MD; Rita C. Seabrook, PhD; Vijay Singh, MD
}

From the School of Social Work (SJ Lee, JY Lee, R Tolman), University of Michigan, Ann Arbor, Mich; Sandra Rosenbaum School of Social Work (TB Walsh), University of Wisconsin, Madison, Wis; Department of Pediatrics (C Garfield), Northwestern University Feinberg School of Medicine, Chicago III; Rush Medical College (RC Seabrook), Chicago III; and Departments of Emergency, Family, and Internal Medicine (V Singh), Injury Prevention Center, University of Michigan, Ann Arbor, Mich

The authors have no conflicts of interest to report. There were no corporate sponsors of this research.

Address correspondence to Shawna J. Lee, School of Social Work, University of Michigan, 1080 South University Ave, Ann Arbor, MI 48109 (e-mail: shawnal@umich.edu).

Received for publication August 18, 2020; accepted March 20, 2021.

\section{Abstract}

OBJective: 1) To describe young men's knowledge of infant routines, discipline, development, safety, sleep, and nutrition, using items assessing the American Academy of Pediatrics Bright Futures: Guidelines for Health Supervision of Infants, Children, and Adolescents. 2) To report differences in knowledge between fathers and non-fathers. 3) To examine factors associated with men's greater knowledge.

MetHOdS: Participants were men $(\mathrm{N}=1303)$ aged 18 to 35 years responding to a cross-sectional survey that was administered to a national panel established through probability sampling of the civilian, non-institutionalized US population. Survey weights allow reporting of nationally representative analyses.

RESULTS: Participants (mean age $=27 ; 58 \%$ white, $36 \%$ fathers) correctly answered 52\% of the infant knowledge questions. Fathers and non-fathers answered $64 \%$ and $46 \%$ of the items correctly, respectively. The difference in knowledge between fathers and non-fathers was statistically significant
( $B=0.16, P<.001)$. The subscale with the highest number of correct responses was routines ( $80 \%$ accuracy), followed by discipline (59\% accuracy), safety (52\% accuracy), sleep (51\% accuracy), development (50\% accuracy), and nutrition (40\% accuracy). Multivariate analyses showed that depressive symptoms $(B=-0.07, P<.05)$ were associated with lower infant knowledge, while higher education $(B=0.06, P<.05)$ and current employment $(B=0.06, P<.01)$ were associated with higher infant knowledge.

Conclusions: Significant gaps exist in men's knowledge of infant development. Pediatric health care providers can address gaps in parenting knowledge by providing anticipatory guidance to fathers.

KeYwords: Bright Futures Guidelines; pediatrics; infant health; parent education; fathers

Academic Pediatrics 2021;XXX:1-8

\section{What'S NEW}

Research on infant development largely excludes men. No nationally representative studies have examined men's knowledge of infant development. This study provides new information regarding what fathers and non-fathers know about babies and has implications for intervention by health care providers.

PARENTING KNOWLEDGE IS defined as understanding child development, developmental norms and milestones, processes underlying development, and child caregiving. ${ }^{1,2}$ Parenting knowledge in the domains of routines, children's health and safety, nutrition, and discipline are a critical first step in promoting child wellbeing. ${ }^{1}$ Parenting knowledge in these domains helps parents establish responsive care routines, engage in safe sleep practices, provide good nutrition, and practice developmentally appropriate parenting. $^{2-4}$

Anticipatory guidance refers to the topics on which pediatric professionals counsel and educate parents. ${ }^{1}$ The
American Academy of Pediatrics (AAP), Bright Futures: Guidelines for Health Supervision of Infants, Children, and Adolescents, 4th Edition, ${ }^{5}$ are the most widely used anticipatory guidance for pediatric health care professionals in the United States. The delivery of anticipatory guidance is associated with increased parenting knowledge of infant development and improved parenting behaviors related to discipline, safety, and early reading. ${ }^{6}$ Even with anticipatory guidance provided to many parents-mainly mothers-during the perinatal period, many first time parents indicated they lacked parenting knowledge they needed and wanted. ${ }^{2}$

\section{Fathers and Parenting Knowledge}

Most fathers of young children are actively involved in caregiving. About $72 \%$ of residential fathers fed or ate meals with their child daily, and $90 \%$ bathed, diapered or dressed the child, or helped their child with such activities daily or several times a week. ${ }^{7}$ About $8 \%$ of nonresidential fathers fed or ate meals with their child daily and $31 \%$ 
bathed, diapered or dressed the child, or helped their child with such activities daily or several times a week. ${ }^{7}$ Both residential and nonresidential fathers attend pediatric well-child visits and contribute to health care decisions for their children. ${ }^{8}$ Even so, fathers spend less time on childcare than mothers and may have less knowledge as they transition to parenthood. ${ }^{9,10}$ Research indicates that, compared to mothers, fathers receive less support and advice related to parenting, ${ }^{11}$ and fathers are more likely to rely on informal sources of parenting knowledge (their partner, friends, and family members) as compared to websites, books, and other professional sources. ${ }^{12,13}$

Professionals recognize the importance of counseling fathers, ${ }^{14,15}$ yet mothers are the primary focus of guidance and intervention during the perinatal period. ${ }^{15-17}$ There has been minimal research on fathers' parenting knowledge related to anticipatory guidance. ${ }^{2,8,10}$ One study of 203 US parents found that mothers had higher levels of parenting knowledge than fathers, pointing to a potential gap in knowledge among fathers. ${ }^{10}$ A qualitative study of US mothers and fathers found that most parents knew basic information about infant care, but this study did not specifically report fathers' levels of knowledge. ${ }^{18}$

\section{The Current Study}

This study reports the results of a nationally representative survey of young adult men that included fathers and non-fathers, aged 18 to 35 years. The average age of first birth for men in the United States is 25 . The majority $(\sim 66 \%)$ of first births to men occurs during their twenties, and about 1 out of 5 first births occur to men who are age 30 or older. ${ }^{19}$ By the age of $40,76 \%$ of men have fathered at least one child. ${ }^{19}$ Thus, ages 18 to 35 years encompasses the time period when most men will become parents. ${ }^{20}$ First, we describe men's knowledge of anticipatory guidance from the AAP Bright Futures: Guidelines for Health Supervision of Infants, Children, and Adolescents. We hypothesized that respondents would demonstrate less than $75 \%$ accuracy, measured by responses to individual items and scales. Second, we examined differences in knowledge between fathers and non-fathers. We hypothesized that fathers would know more about infant development than non-fathers, based on knowledge gained during the transition to parenthood. Third, we assessed whether depressive symptoms, sociodemographic factors, and parenting experience were associated with men's knowledge of infant development and health promotion. Similar to research with women with low income, ${ }^{21}$ we hypothesized that men with lower levels of educational attainment would know less about infant development. ${ }^{22,23}$ Further, based on research showing that paternal depression is common, and is associated with men's parenting risk behaviors, ${ }^{24-26}$ we examined whether paternal depression might be associated with lower levels of parenting knowledge.

\section{MetHOD}

\section{Procedure}

We conducted a cross-sectional survey (August and September 2014) of participants from the KnowledgePanel (IPSOS, https://www.ipsos.com/en-us/solutions/pub lic-affairs/knowledgepanel), a national panel of 55,000 US adults established through probability sampling of the civilian, non-institutionalized US population that has been used widely in health care research. Panel members were chosen though random-digit dialing and address-based sampling, and households without Internet connection were provided with a web-enabled device and free Internet service. KnowledgePanel sent 2 e-mail reminders and one interactive voice response telephone reminder. We distributed 2889 surveys to men aged 18 to 35 and had a $47 \%$ response rate. Only $3 \%$ of the sample $(n=43)$ had missing data (analytic sample $=1303$ ). The participants received self-read informed consent. The human subjects' protections for this study were reviewed and approved by the University of Michigan Health Sciences and Behavioral Sciences Institutional Review Board.

\section{Participants}

Men $(\mathrm{N}=1303)$ aged 18 to 35 years $(\mathrm{M}=27.53$; $\mathrm{SD}=4.82$ ) participated in an online survey of men's health and wellbeing. Thirty-six percent of the respondents indicated that they were fathers to biological, step-, adopted or foster children. Among those who were fathers, the mean number of children was approximately 2 (mean $=1.99 ;$ mode $=2 ; \mathrm{SD}=1.24 ;$ range $1-10)$. Most fathers $(70 \%)$ had at least one child younger than 5 years. See Table 1 for respondent characteristics.

\section{Measures}

Opinions about Babies ${ }^{21}$ is a criterion-referenced scale that measures knowledge of typical infant development derived from the Bright Futures Guidelines ${ }^{27}$ and the AAP Guidelines for Health Supervision II. ${ }^{28}$ Each Opinions about Babies item targets information that pediatric professionals have determined parents should know, and thus the Opinions about Babies measure constitutes a professional-based criterion of knowledge. We used 32 items that assess knowledge regarding cognitive and physical development, safety issues, discipline, feeding and nutrition, daily routines, and infant sleep habits. Because our interest was in men's knowledge of typical infant development, we excluded 3 items about maternal health after birth. Each item includes a statement (Table 2) pertaining to infant development, with responses categories: disagree, agree, or no opinion. Correct answers were scored as 1 , incorrect answers were scored as 0 , and no opinion responses were categorized as incorrect or 0 to reflect lack of knowledge in that domain.

Depressive symptoms during the past 2 weeks were measured with the Patient Health Questionnaire (PHQ$2)^{29}$ : "Over the last 2 weeks, how often have you been bothered by any of the following problems?" 1) "little 
Table 1. Respondent Characteristics, National Survey of Men Aged 18-35 Years $(N=1303)$

\begin{tabular}{|c|c|c|c|c|}
\hline Variable & Full Sample & $\begin{array}{c}\text { Non-fathers } \\
(\mathrm{N}=837 ; 64 \%)\end{array}$ & $\begin{array}{c}\text { Fathers } \\
(N=466 ; 36 \%)\end{array}$ & $P$ \\
\hline OAB mean score, $\%$ correct & 52 & 46 & 64 & $<.001$ \\
\hline Depression symptoms (PHQ), \% yes & 11 & 13 & 7 & $<.001$ \\
\hline Age in years & 27 & 25 & 29 & $<.001$ \\
\hline \multicolumn{5}{|l|}{ Race and ethnicity, \%: } \\
\hline White & 58 & 59 & 57 & NS \\
\hline African American & 11 & 11 & 12 & \\
\hline Hispanic & 22 & 20 & 24 & \\
\hline Other & 9 & 10 & 7 & \\
\hline \multicolumn{5}{|l|}{ Education level, \%: } \\
\hline$<$ high school & 14 & 14 & 16 & NS \\
\hline High school degree & 30 & 29 & 31 & \\
\hline Some college & 33 & 33 & 33 & \\
\hline BA or higher & 23 & 24 & 20 & \\
\hline Annual household income & $\$ 45,000$ & $\$ 45,000$ & $\$ 55,000$ & NS \\
\hline Employment status, \% yes & 70 & 62 & 85 & $<.001$ \\
\hline \multicolumn{5}{|l|}{ Relationship status, \% yes } \\
\hline Married, widowed, divorced, separated & 37 & 19 & 72 & $<.001$ \\
\hline Cohabiting & 11 & 10 & 13 & \\
\hline Never married & 52 & 71 & 15 & \\
\hline No. of children in household, M & & & 2 & \\
\hline
\end{tabular}

$M$ indicates mean; OAB, Opinions about Babies; PHQ, Patient Health Questionnaire; No., number.

Note: Full sample mean age $=27.53 ; S D=4.82$; range $18-35$. For fathers only, mean number of children was approximately 2 (mean $=1.99 ;$ mode $=2 ; S D=1.24 ;$ range $1-10$ ).

Rows and columns may not add to $100 \%$ due to rounding. Table presents means and proportions adjusted for national sample probability weights. Omnibus (Wald) chi-square tests were conducted for binary and categorical variables (denoted as \%). $t$ test analyses were conducted to compare fathers to non-fathers; $P$-values are presented in the last column.

interest or pleasure in doing things" and 2) "feeling down, depressed, or hopeless." Response options were "not at all," "several days," "more than half the days," and "nearly every day," scored as $0,1,2$, and 3 , respectively. A summed score of 3 or higher indicates probable depression.

Fathering status was determined by asking the following question: "Counting all of your relationships, current and previous, have you fathered any children? Please respond 'yes' if you have experience as a father to one or more biological children, step-children, adopted children, and foster children, or if there are any other children for whom you are/were in a significant fathering role."

Sociodemographic questions pertained to respondents' age, race or ethnicity (white, African American, Hispanic, and other race or biracial), education level, household income, employment status, relationship status, number of children in the household, and age of child/ children.

\section{Analysis Plan}

We removed from analyses individuals who were missing data on key study variables included in the regression model (Table 3), resulting in a final analytic sample of 1303 men. Analysis of the unweighted data showed that, in comparison to those in the Knowledge panel, respondents in the current survey were older [t $(2887)=4.00, P<$ $.001]$, less likely to be Hispanic or African-American $\left[\chi^{2}(4)=47.75, P<.001\right]$, had a higher income $\left[\chi^{2}(7)=\right.$ 42.32, $P<.001]$, and were more educated $\left[\chi^{2}(3)=65.90\right.$, $P<.001]$. When weighted, the data collected via the panel yields nationally representative estimates for non-incarcerated adult men aged 18 to 35 years. Poststratification weights were used in order to ensure that the sample was representative of the US population. Weighting was based on gender, age, race, education, census region, annual household income, home ownership status, metropolitan area (yes/no), and internet access (yes/no) from the most recent (based on time of data collection) March supplement of the Current Population Survey. We applied survey weights to reduce bias in demographic differences between those who did and did not complete surveys.

We first conducted univariate analyses to describe the level of knowledge measured by Opinions about Babies, depressive symptoms, and sociodemographic characteristics of the sample. We also conducted bivariate analyses comparing non-fathers and fathers in these domains. Second, we conducted item-by-item univariate analyses of the infant development and knowledge subscales, indicating the percent of respondents that correctly answered each item. We again conducted bivariate analyses comparing fathers and non-fathers on Opinions about Babies individual items and subscales. Omnibus chi-square tests or $t$-tests were used to compare fathers and non-fathers; these analyses were adjusted using the probability sampling survey weight (Tables 1 and 2). Third, we conducted multivariate linear regression models to examine correlates of level of knowledge including depressive symptoms and sociodemographic characteristics, controlling for fathering status in order to examine whether fathers had significantly higher scores on the Opinions about Babies scale compared with non-fathers. 
Table 2. Percent of Men With Correct Responses to Opinions About Babies Scale $(N=1303)$

\begin{tabular}{|c|c|c|c|c|}
\hline & \multicolumn{3}{|c|}{$\%$ Correct } & \multirow[b]{2}{*}{$P$} \\
\hline & All Men & $\begin{array}{l}\text { Non-fathers } \\
(\mathrm{N}=837 ; 64 \%)\end{array}$ & $\begin{array}{c}\text { Fathers } \\
(\mathrm{N}=466 ; 36 \%)\end{array}$ & \\
\hline $\begin{array}{l}\text { Overall mean score for the } \mathrm{OAB} \text {, including all } \\
\text { subsections }\end{array}$ & 52 & 46 & 64 & $<.001$ \\
\hline Subsection: Routines & 80 & 76 & 88 & $<.001$ \\
\hline It is important to have regular bedtime routines for babies. & 83 & 80 & 88 & $<.001$ \\
\hline Having a normal naptime and bedtime is important for babies. & 82 & 79 & 88 & $<.01$ \\
\hline Routines are important for babies to feel secure. & 76 & 70 & 88 & $<.001$ \\
\hline Subsection: Discipline & 59 & 54 & 69 & $<.001$ \\
\hline $\begin{array}{l}\text { It is important to let babies and children know when they are } \\
\text { being good or doing something right. }\end{array}$ & 85 & 81 & 93 & $<.001$ \\
\hline Babies learn from watching what their parents do. & 85 & 81 & 92 & $<.001$ \\
\hline $\begin{array}{l}\text { When children see their parents scream they learn that it is } \\
\text { OK to scream. }\end{array}$ & 64 & 58 & 76 & $<.001$ \\
\hline Discipline means to punish. (RS) & 61 & 58 & 68 & $<.01$ \\
\hline Spanking is the best way to teach a baby how to behave. (RS) & 62 & 55 & 74 & $<.001$ \\
\hline $\begin{array}{l}\text { It helps to get children to look or play with something else } \\
\text { when they misbehave. }\end{array}$ & 34 & 26 & 50 & $<.001$ \\
\hline Spanking teaches children that hitting is OK. & 23 & 20 & 29 & $<.01$ \\
\hline Subsection: Safety & 52 & 44 & 67 & $<.001$ \\
\hline Hard foods like popcorn or carrots are dangerous for babies. & 76 & 71 & 85 & $<.001$ \\
\hline $\begin{array}{l}\text { If an object is the same size as a quarter, then it is too big for a } \\
\text { baby to choke on it. (RS) }\end{array}$ & 59 & 55 & 69 & $<.001$ \\
\hline Babies are safer if they sleep on their backs. & 49 & 40 & 66 & $<.001$ \\
\hline $\begin{array}{l}\text { It is OK to give honey to a baby that is less than one year old. } \\
\text { (RS) }\end{array}$ & 42 & 33 & 60 & $<.001$ \\
\hline $\begin{array}{l}\text { Once a baby turns } 6 \text { months, the car seat should be front fac- } \\
\text { ing. (RS) }\end{array}$ & 33 & 21 & 55 & $<.001$ \\
\hline Subsection: Sleep & 51 & 47 & 59 & $<.001$ \\
\hline It is important to have regular bedtime routines for babies. & 83 & 80 & 88 & $<.001$ \\
\hline Having a normal naptime and bedtime is important for babies. & 82 & 79 & 88 & $<.01$ \\
\hline Babies are safer if they sleep on their backs. & 49 & 40 & 66 & $<.001$ \\
\hline $\begin{array}{l}\text { By 6-months-old, babies spend more time awake than asleep. } \\
\text { (RS) }\end{array}$ & 25 & 21 & 32 & $<.001$ \\
\hline $\begin{array}{l}\text { Feeding babies cereal does not help them sleep through the } \\
\text { night. }\end{array}$ & 15 & 12 & 21 & $<.001$ \\
\hline Subsection: Development & 50 & 44 & 63 & $<.001$ \\
\hline $\begin{array}{l}\text { Babies will copy what an adult does, such as sticking a tongue } \\
\text { out or making silly noises. }\end{array}$ & 81 & 77 & 90 & $<.001$ \\
\hline $\begin{array}{l}\text { Talking to babies is better than listening to the TV or radio for } \\
\text { teaching them to talk. }\end{array}$ & 75 & 69 & 87 & $<.001$ \\
\hline Newborns know their mother's and father's voice. & 73 & 66 & 89 & $<.001$ \\
\hline $\begin{array}{l}\text { Most 18-month-old children are able to sit quietly at a dinner } \\
\text { table for an hour while everyone else eats. (RS) }\end{array}$ & 62 & 56 & 72 & $<.001$ \\
\hline A baby's brain develops when they think. & 54 & 50 & 62 & $<.01$ \\
\hline Babies like bright colors best. & 49 & 42 & 64 & $<.001$ \\
\hline $\begin{array}{l}\text { For the first few months, babies like toys more than faces. } \\
\text { (RS) }\end{array}$ & 42 & 34 & 59 & $<.001$ \\
\hline $\begin{array}{l}\text { At } 6-8 \text { months, babies begin to be afraid of people they do not } \\
\text { know. }\end{array}$ & 37 & 31 & 51 & $<.001$ \\
\hline Newborns are not able to smell with their noses. (RS) & 37 & 33 & 45 & $<.001$ \\
\hline $\begin{array}{l}\text { Babies' brains stay the same size until they are 1-year-old. } \\
\text { (RS) }\end{array}$ & 33 & 27 & 45 & $<.001$ \\
\hline Newborns can only see 8-12 inches from their face. & 31 & 23 & 48 & $<.001$ \\
\hline It is not possible to spoil a child less than 4 months old. & 28 & 22 & 40 & $<.001$ \\
\hline Subsection: Nutrition & 40 & 32 & 55 & $<.001$ \\
\hline Breast milk helps keep babies healthier than formula. & 67 & 60 & 81 & $<.001$ \\
\hline $\begin{array}{l}\text { It is OK to give honey to a baby that is less than one year old. } \\
\text { (RS) }\end{array}$ & 42 & 33 & 60 & $<.001$ \\
\hline Babies should eat on a strict schedule. (RS) & 27 & 20 & 39 & $<.001$ \\
\hline $\begin{array}{l}\text { Baby food and cereal should be given to babies when they are } \\
3 \text { months old. (RS) }\end{array}$ & 24 & 16 & 41 & $<.001$ \\
\hline
\end{tabular}

RS indicates reverse scored.

Note: Rows and columns may not add to $100 \%$ due to rounding. Table presents means and proportions adjusted for national sample probability weights. $t$ test analyses were conducted to compare fathers to non-fathers; $P$-values are presented in the last column. 
Table 3. Linear Regression Model Examining Predictors of Opinions About Babies Scale $(N=1303)$

\begin{tabular}{|c|c|c|c|}
\hline Variable & Coef & $(95 \% \mathrm{Cl})$ & $P$ \\
\hline Depression symptoms (PHQ) & -0.07 & $(-0.12$ to 0.01$)$ & $<.05$ \\
\hline Father (yes or no) & 0.16 & $(0.11-0.22)$ & $<.001$ \\
\hline Age & -0.01 & $(-0.01$ to 0.00$)$ & $<.05$ \\
\hline \multicolumn{4}{|l|}{ Race or ethnicity } \\
\hline White & 1 [Reference] & & \\
\hline African American & -0.08 & $(-0.14$ to 0.02$)$ & $<.05$ \\
\hline Hispanic & -0.02 & $(-0.06$ to 0.02$)$ & - \\
\hline Other race or biracial & -0.04 & $(-0.10$ to 0.02$)$ & - \\
\hline \multicolumn{4}{|l|}{ Education level } \\
\hline Less than high school & 1 [Reference] & & \\
\hline High school or equivalent & -0.03 & $(-0.08$ to 0.03$)$ & - \\
\hline Some college & 0.05 & $(-0.01$ to 0.11$)$ & - \\
\hline Bachelor's degree or higher & 0.06 & $(0.00$ to 0.13$)$ & $<.05$ \\
\hline Annual household income & 0.00 & $(0.00$ to 0.00$)$ & - \\
\hline Employment status (yes or no) & 0.06 & $(0.02$ to 0.10$)$ & $<.01$ \\
\hline \multicolumn{4}{|l|}{ Relationship status } \\
\hline Married & 1 [Reference] & & \\
\hline Cohabiting (not married) & 0.01 & $(-0.04$ to 0.06$)$ & - \\
\hline Never married & -0.03 & $(-0.07$ to 0.02$)$ & - \\
\hline No. of children in household & 0.00 & $(-0.01$ to 0.02$)$ & - \\
\hline
\end{tabular}

OAB indicates Opinions about Babies; PHQ, Patient Health Questionnaire; No., number.

Note: Table presents adjusted coefficients and confidence intervals using probability sampling weights.

\section{RESULtS}

\section{DESCRIPTIVE INFORMATION}

As shown in Table 1, overall participants correctly answered $52 \%$ of the infant development and knowledge questions. Fathers had significantly higher levels of knowledge than non-fathers $(P<.001)$ with fathers answering $64 \%$ of the items correctly, and non-fathers answering $46 \%$ of the items correctly.

Table 2 presents the subscale and item level responses for all study respondents, including comparisons of fathers and non-fathers. Fathers had higher levels of accuracy than did non-fathers on all of the subscales and all of the items. When looking at items by subscale, the subscale with the highest number of correct responses was routines ( $80 \%$ accuracy), followed by discipline (59\% accuracy), safety (52\% accuracy), sleep (51\% accuracy), development (50\% accuracy), and nutrition (40\% accuracy).

\section{Multivariate Analyses}

Table 3 presents weighted multivariate linear regression models to examine correlates of men's level of knowledge, including fathers and non-fathers in the sample. As expected from the bivariate analyses, fathers had significantly higher levels of knowledge than did nonfathers $(B=0.16, P<.001)$. Individuals reporting more depressive symptoms demonstrated lower levels of knowledge, even after controlling for factors such as education level and race or ethnicity.

Sociodemographic factors were also associated with men's level of knowledge. Being of older age (ie, older fathers, on the scale from 18-35 years of age) was associated with lower levels of knowledge. African American fathers had lower levels of knowledge than white fathers, and respondents with higher levels of education had greater knowledge compared with those with less than a high school degree. Additionally, men who were employed-about $70 \%$ of the sample-had higher levels of knowledge than those who were not employed.

\section{Discussion}

This study examined young fathers' and non-fathers' knowledge of typical infant development and correlates with demographic and psychosocial factors. Study results suggested that among a nationally representative sample of men aged 18 to 35 years, including fathers and nonfathers, there were low levels of knowledge about common anticipatory guidance topics related to infant development, developmental milestones, and infant health promotion. As expected, fathers consistently had greater levels of knowledge compared with non-fathers. Multivariate analyses indicated that depressive symptoms, older age, and African American race were factors associated with lower levels of infant knowledge. Those with higher education levels and who were employed had higher levels of infant knowledge.

Proper knowledge of how to care for young children, how they grow, and how parents can meet their physical and emotional needs can improve parenting behaviors and, subsequently, child outcomes. ${ }^{1}$ Although men in this study reported $80 \%$ accuracy in knowledge of caregiving routines, there were only three questions in the routines subsection. Study results indicated lower levels of knowledge in other infant care domains-discipline, safety, nutrition, and sleep-with respondents scoring well below $75 \%$ in those domains.

The finding that men had relatively low levels of knowledge of infant development is consistent with prior research suggesting that mothers lacked important information about key infant health factors, such as infant sleep patterns and developmental ability. ${ }^{21}$ In one study of 
mothers with low income, respondents correctly answered $65 \%$ of criterion-referenced infant knowledge questions based on the AAP Bright Futures Guidelines. Mothers showed the least knowledge about infant sleep patterns and developmental ability of 6-month-old infants. ${ }^{21}$ Another study suggested that parenting risk factors were associated with lower levels of maternal knowledge of infant development and milestones. ${ }^{30}$

The results of the current study are also consistent with parents' perceptions of their own gaps in knowledge based on information from focus groups with first time parents. ${ }^{31}$ Furthermore, a systematic review concluded that parents lacked the parenting knowledge they felt they needed. ${ }^{2}$ Efforts to improve men's parenting knowledge in infant care and development are important given research that such knowledge can promote positive parenting behaviors and child outcomes. ${ }^{1,2}$ Overall, fathers and many mothers demonstrate gaps in parenting knowledge, with individuals from certain higher risk groups (eg, low income, those with depressive symptoms) potentially standing to gain the most from greater exposure to anticipatory guidance.

The current study results suggest that fathers have significantly more infant development knowledge than nonfathers, which may reflect fathers' greater motivation to learn about infant development and caregiving, and experiential learning "on the job" as men transition to parenthood. Indeed, prior research indicates that expectant fathers are motivated to learn about what to expect as a new father, ${ }^{11,12,32-34}$ and they would benefit from greater infant development knowledge to prepare for the transition to fatherhood. Information regarding men's knowledge gaps could help professionals working with parents to design and tailor interventions targeted to fathers' needs. Furthermore, the knowledge gap between fathers and non-fathers or future fathers suggests the importance of augmenting men's knowledge prior to the birth of a child.

Study results indicate that lower levels of men's knowledge were correlated with depressive symptoms and sociodemographic factors. Prior research suggests that paternal depression is associated with poorer parenting for men, ${ }^{24-26}$ yet efforts to screen for and treat perinatal paternal depression lag behind those for mothers. ${ }^{8}$ During the transition to parenthood, men who are experiencing higher levels of depressive symptoms may need more prompting to learn about the developmental needs of children.

Study findings also indicate that men with higher education level and those who were employed had more knowledge, compared to men with lower levels of education or who were unemployed. Parents with higher levels of education typically know more about child development and effective parenting methods, compared to parents with lower levels of education. ${ }^{1,22,23}$ Parents with lower levels of education may face barriers in their ability to access accurate and credible parenting information. ${ }^{1}$ An implication is that health care providers may need to concentrate educational efforts to serve men with lower levels of education early on, so that they are better prepared to parent. Such efforts may help men play a role in promoting their children's health and wellbeing.

Finally, older participants in this study (measured from 18 to 35 years of age) had lower levels of knowledge of infant development and health promotion. However, it is difficult to interpret this finding given that the age range of this survey was purposively truncated (respondents were 18-35 years old) and therefore, did not represent the full spectrum of ages of men.

\section{IMPLICATIONS FOR INTERVENTION}

Multiple organizations have highlighted the need for policies and programs to promote parenting knowledge as a way to optimize child development and wellbeing. ${ }^{1}$ Researchers and practitioners alike recognize the need for father-inclusive programs and practices that better engage fathers. As noted previously, fathers are more likely to receive parenting support and knowledge from informal sources. ${ }^{12,13}$ There are few formal father-inclusive parent education interventions. ${ }^{17}$ As a result, men receive little guidance, support, or education in the transition to fatherhood. ${ }^{11,33,35}$ This suggests great need for more formal programs to provide evidence-based parenting education to men during the perinatal period.

Relatedly, most health care providers who work with patients during the perinatal period $\backslash$ are not well trained to interact with fathers in clinical settings. ${ }^{8}$ Factors such as comfort in interacting with men and addressing fathers' unique concerns about parenting remain barriers to effectively engaging fathers in services. ${ }^{8}$ The AAP recommends active support of fathers, as fathers and mothers alike would benefit from a family-centered care model that acknowledges the importance of fathers, but implementation is still lacking. At the earliest well child visits, and even earlier in the context of prenatal care, anticipatory guidance directed toward fathers offers an important opportunity for engagement and relationship building. That is, it may help to initiate relationships between fathers and children's health care providers that can be developed over time and thus, ultimately benefit children's health and wellbeing.

Most men attend a prenatal ultrasound visit. ${ }^{35}$ Perinatal health care encounters may provide an opportunity to provide anticipatory guidance. During perinatal visits, pediatric, family medicine, and obstetrical health care providers may be able to build fathers' knowledge, boost their confidence, and establish the foundation for positive parenting behaviors. Anticipatory guidance delivered early on during the perinatal period may provide particularly positive outcomes.

During the era of the COVID-19 pandemic, many health care settings limited the number of people who could attend health care visits. This may be especially disadvantageous to expecting and new fathers, who may not be able to access health care providers during routine ultrasound visits or well child visits. Even so, there is some evidence that providers attempted to expand video visits so that both parents could attend. Anecdotally, in 
health care settings where the authors of the current study work, more parents were using patient portal access to participate in video visits and to receive child developmental questions. Video visits and patient portal access can both serve as ways to engage fathers.

The results of this study can help to prioritize topics for anticipatory guidance for fathers that can begin in pregnancy. Among fathers, two thirds or less responded correctly to items assessing knowledge of safety, development, sleep, and nutrition, and a lower proportion of possible future fathers responded correctly to these items. Only $40 \%$ of all men and 32\% of non-fathers responded correctly to items about infant nutrition. Thus, nutrition may be a critical area for anticipatory guidance for men as they transition to their roles as parents. Prenatal and pediatric care providers may be able to promote better outcomes for children by engaging fathers and providing necessary anticipatory guidance in nutrition, as well as infant sleep, development, and safety.

\section{Limitations and Directions for Future Research}

Age range (18-35) was purposively truncated and, as a result, findings related to age cannot be generalized to the full population of fathers, who encompass a wider age span. The study was cross-sectional, therefore, no causal mechanisms can be established. There were demographic differences between respondents and nonrespondents: respondents were older, less likely to be Hispanic or African-American, had a higher income, and were more educated. Poststratification weights were applied to reduce this bias.

In analyses comparing fathers to non-fathers, the nonfathers group most likely includes those who intend to be fathers one day and those who do not. Furthermore, knowledge may be higher for fathers of very young children. Fathers of older children may have forgotten information about infancy and early childhood. We note that $70 \%$ of fathers had at least one child younger than 5 years at the time of survey completion, limiting this concern. Finally, this study is descriptive in nature. We do not have information on men's experiences of caring for children or other potential risk factors (ie, father's anxiety). Future research could compare knowledge among men who intend to become fathers one day and fathers of infants, to more precisely assess the gap in knowledge that exists between likely future fathers and new fathers and illuminate the knowledge needs of men prior to fatherhood.

This study included only men, therefore we are unable to compare how men and women differ in their parenting knowledge. Future research may wish to consider how non-parent men and women, and how fathers and mothers, may differ in their parenting knowledge. We also do not consider a wide range of explanatory factors in knowledge, such as parenting socialization processes.

\section{Conclusions}

More research is needed to understand the specific ways pediatric health care providers can most effectively engage fathers, alongside mothers, when offering anticipatory guidance. Best practices for engaging fathers in clinical settings should be identified and evaluated.

\section{ACKNOWLEDGMENTS}

Funding statement: This research was supported by grants from the Robert Wood Johnson Foundation and the Veterans Affairs Clinical Scholars Program to Dr. Vijay Singh. The funders were not involved in the design or execution of the study.

\section{References}

1. National Academies of Sciences, Engineering, and Medicine. Parenting Matters: Supporting Parents of Children Ages 0-8. Washington DC: The National Academies Press; 2016

2. Bartlett JD, Karberg E, Bringewatt E, et al. First-Time Parents Knowledge of Infant and Toddler Development: A Review of the Literature. Bethesda, MD: Child Trends; 2017, August.

3. Regalado M, Halfon N. Primary care services promoting optimal child development from birth to age 3 years: review of the literature. Ach Pediatr Adolesc Med. 2001;155:1311-1322.

4. Bartlett JD, Guzman L, Ramos-Olazagasti MA. Parenting Knowledge Among First-Time Parents of Young Children: A Research-toPractice Brief. Bethesda, MD: Child Trends; 2018, July.

5. Hagan JF, Shaw JS, Duncan PM. Bright Futures: Guidelines for Health Supervision of Infants, Children, and Adolescents, 4th Edition. Itasca, IL: American Academy of Pediatrics; 2017.

6. Johnston BD, Huebner CE, Anderson ML, et al. Healthy steps in an integrated delivery system: child and parent outcomes at 30 months. Arch Pediatr Adolesc Med. 2006;160:793-800.

7. Jones J, Mosher WD. Fathers' involvement with their children: United States, 2006-2010. Natl Health Stat Rep. 2013;71:1-21.

8. Yogman MW, Garfield CF. Fathers' roles in the care and development of their children: the role of pediatricians. Pediatrics. 2016;138: e20161128.

9. Scarzello D, Arace A, Prino LE. Parental practices of Italian mothers and fathers during early infancy: the role of knowledge about parenting and child development. Infant Behav Dev. 2016;44:133-143.

10. Vally Z, Hichami F. Knowledge about parenting as a predictor of behavioral discipline practices between mothers and fathers. Psychol Stud. 2020;65:40-50.

11. Radey M, Randolph KA. Parenting sources: how do parents differ in their efforts to learn about parenting? Fam Relat. 2009;58:536-548.

12. Dayton CJ, Buczkowski R, Muzik M, et al. Expectant fathers' beliefs and expectations about fathering as they prepare to parent a new infant. Soc Work Res. 2016;40:225-236.

13. Pew Research Center. Parenting in America: outlook, worries, aspirations are strongly linked to financial situation.2015, December.

14. Aqil A, Allport BS, Johnson SB, et al. Content to share with expectant fathers: views of professionals focused on father involvement. Midwifery. 2019;70:119-126.

15. Allport BS, Solomon BS, Johnson SB. The other parent: an exploratory study of providers' engagement of fathers in pediatric primary care. Clin Pediatr. 2019;58:555-563.

16. Combs-Orme T, Holden Nixon B, Herrod HG. Anticipatory guidance and early child development: pediatrician advice, parent behaviors, and unmet needs as reported by parents from different backgrounds. Clin Pediatr. 2011;50:729-737

17. Lee JY, Knauer HA, Lee SJ, et al. Father-inclusive perinatal parent education programs: a systematic review. Pediatrics. 2018;142: e20180437.

18. Ateah CA. Prenatal parent education for first-time expectant parents: "Making It Through Labor Is Just the Beginning.... J Pediatr Healthcare. 2013;27:91-97.

19. Martinez G, Daniels K, Chandra A. Fertility of Men And Women Aged 15-44 Years in the United States: National Survey of Family Growth, 2006-2010. Hyattsville, MD: National Center for Health Statistics; 2012. 
20. Allred CA, Guzzo KB. Men's Birth Expectations, FP-18-12. OH: National Center for Family \& Marriage Research. Bowling Green State University; 2018.

21. Reich S. What do mothers know? Maternal knowledge of child development. Infant Mental Health J. 2005;26:142-156.

22. Nobre-Lima L, Vale-Dias ML, Mendes TV, et al. The Portuguese version of the Knowledge of Infant Development Inventory-P (KIDI-P). Eur J DevPsychol. 2014;11:740-745.

23. Bornstein MH, Cote LR, Haynes OM, et al. Parenting knowledge: experiential and sociodemographic factors in European American mothers of young children. Dev Psychol. 2010;46:1677.

24. Davis RN, Davis MM, Freed GL, et al. Fathers' depression related to positive and negative parenting behaviors with 1-year old children. Pediatrics. 2011;127:611-619. https://doi.org/10.1542/peds. 2010-1779.

25. Lee SJ, Taylor CA, Bellamy JL. Paternal depression and child neglect in father-involved families of young children. Child Abuse \& Neglect. 2012;36:461-469.

26. Lee SJ. Paternal and household characteristics associated with child neglect and Child Protective Services involvement. J Soc Serv Res. 2013;39:171-187.

27. Green M, Palfrey J. Bright Futures: Guidelines for Health Supervision of Infants, Children, and Adolescents. Arlington, VA: National Center for Education in Maternal and Child Health; 2002.
28. American Academy of Pediatrics. Guidelines for Health Supervision III. Elk Grove, IL: Author; 1997.

29. Kroenke K, Spitzer RL, Williams JB. The patient health questionnaire-2: validity of a two-item depression screener. Medical Care. 2003;41:1284-1292.

30. Britner PA, Reppucci ND. Prevention of child maltreatment: Evaluation of a parent education program for teen mothers. J Child Fam Stud. 1997;6:165-175.

31. Guzman L, Ramos-Olazagasti M, Miller E, et al. First-Time Parents' Knowledge of Early Child Development: Focus Group Report. Bethesda, MD: Child Trends; 2018, April.

32. Lee SJ, Yelick A, Brisebois K, et al. Low-income fathers' barriers to participation in family and parenting programs. J Fam Strengths. 2011;11:1-16. Available at: http://digitalcommons.library.tmc.edu/ jfs/vol11/iss11/12.

33. Lee SJ, Hoffman G, Harris D. Community-based participatory research (CBPR) needs assessment of parenting support to fathers. Child Youth Serv Rev. 2016;66:76-84.

34. Lee SJ, Neugut TB, Rosenblum KL, et al. Sources of parenting support in early fatherhood: perspectives of United States Air Force members. Child Youth Serv Rev. 2013;35:908-915.

35. Walsh TB, Tolman RM, Singh V, et al. Expectant fathers' presence at prenatal ultrasounds: an opportunity for engagement. Social Work Res. 2017;41:181-185. 